\title{
Assessing Performance Efficiency of Information and Communication Technology Industry-Forecasting and Evaluating: The Case in Vietnam
}

\author{
Chia-Nan Wang, Thi-Duong Nguyen * and Minh-Duyet Le \\ Departments of Industrial Engineering and Management, National Kaohsiung University of Sciences and \\ Technology, Kaohsiung 80778, Taiwan; cn.wang@hi-p.com (C.-N.W.); minhduyet.ithd@gmail.com (M.-D.L.) \\ * Correspondence: duongyennguyen@gmail.com; Tel.: +886-908566040
}

Received: 19 August 2019; Accepted: 18 September 2019; Published: 24 September 2019

\begin{abstract}
The Information and Communication Industry (ICT) plays a very important role in the growth of any nation. Therefore, the ITC sector attracts the great attention of the researcher. Despite many breakthroughs and favorable conditions to develop, the Information and Communication Industry (ICT) of Vietnam stands in a very modest position on the world's ICT map. Therefore, understanding and having an outlook on the performance of companies in this field contribute to the development of the ICT industry in Vietnam. For this reason, the current study is conducted with the main purpose of assessing the performance of 24 Vietnamese ITC companies over past and future periods by applying a hybrid model, including Data Envelopment Analysis (DEA) and Grey model (GM). The author used GM to forecast the future value of inputs and output over period 2018-2022, and then forecasted data is used together with the data of previous years to evaluate the performance of these companies by two models of DEA-Malmquist productivity index (MPI) model and super-SBM-model. This study proposed an approach that can be used by policymakers and decision-makers to develop policies and strategies to sustain the development of the Vietnam ICT industry.
\end{abstract}

Keywords: ICT industry; Data envelopment analysis; Grey model; MPI; Super-SBM; Performance

\section{Introduction}

At present, when the world is changing to a new era of the modern economy, Information and Communication Technology (ICT) will greatly contribute to the development of all countries [1]. The ICT industry is becoming an economic sector with a fast and sustainable growth rate, high turnover, and high export value, contributing significantly to the national GDP [2]. The total number of ICT enterprises nationwide in 2016 is estimated at 24,501 enterprises, increasing 13.13\% compared to 2015. The total revenue of the ICT industry in 2016 is estimated at VND 1,500,009 billion VND (equivalent to 67.693 billion USD, up $11.49 \%$ as compared to 2015). ICT export turnover is estimated at 60.789 billion USD. The total state budget contribution is estimated at VND 34,320 billion (accounting for about $3.4 \%$ of the total state budget). Over the years, the impressive progress and efficiency of ICT for the entire economy, in which its impact on good work has also been recognized [3]. In 2018, the ICT Industry continued to contribute the largest proportion of the total revenue of the Information and Communication Industry with a rapid growth rate, high turnover, and high export value. ICT industry products and services are oriented to create a foundation of knowledge-based economic development, implement the Industrial Revolution 4.0, and contribute to mastering information systems, ensuring national security and national sovereignty; total revenue of ICT industry is estimated at 98.9 billion USD (91.5 billion USD in 2017), export is estimated at 94 billion USD [4]. 
In the past 10 years, Vietnam's ICT rankings have dropped to rank above 100, standing below the world average. Accompanying the Industrial Revolution 4.0 is one of the most important socio-economic developments of our time, the emergence of digital platforms (referred to as platforms) as a model. As a result, the Information and Communication Industry will have an increasing chance to develop their business. However, resources for development investment are limited, making the right investment decisions not only affect the direct benefits of investors but also affect the development of the industry [3]. One of the ways to make investment decisions is based on business results. From the manager's point of view, the study of business results is very important, being vital for the company and making decisions to change investment orientation [4]. Despite the importance of ICT, rare studies examining the performance of ITC companies are founded in literature. Instead, we found numerous studies exploring the impact of ICT on the performance of other aspects, such as service industries, manufacturing industries, energy efficiency, etc.

Taking the importance of the ICT sector and its contributions to the national economy into consideration, there have been many studies examining the performance of this sector. In 1998, Tavares and Antunes conducted a study using DEA to evaluate the performance of telecommunication service in OECD countries [5]. The study of Façanha and Resende [6] introduces an overview of the current trends in the telecommunications sector in Brazil. Pentzaropoulos and Giokas [7] conducted a study comparing the operational efficiency of the main 19 European public telecommunications organizations while using Data Envelopment Analysis. In 2000, the study of Pentzaropoulos and Giokas [8] analyses the change in production efficiency of Greek telecommunication sector. The same topic was studied by Uri [9], which examined the change in production efficiency of local telecom companies in America by applying DEA. Shin and Shon conducted the efficiency measurement of mobile telecom subscriber [10]. Study of Hsiang [11] measured the productivity efficiency of 39 leading global telecom operators by using DEA. George Emm [12] studied the international competition of information and communication technology (ICT) industry by adopting DEA to evaluate the performance of the top 50 ICT companies. Chao [13] examined the Privatization and production efficiency in Taiwan's telecommunications industry by using DEA. Chun and Hsing [14] conducted a study measuring the operational efficiency of six major mobile operators in Japan and Korea over the time period 2002-2006 with the application of DEA. The study of Fukan [15] used the Data Envelopment Analysis and Malmquist Total Factor Productivity Index to measure the technical efficiency of telecom sector over the period of global crisis between the years of 2007-2010 of Turkey and Group of Eight (G8) countries. Emmanouil and Angelo [16] conducted research on the combination between DEA and AHP in producing the priority ranking for a set of companies, the case of the ICT industry. The study of Beatriz [17] examinse investors' valuation of non-financial corporate news items issued by European companies in the information and communications technology industry on a sample of 145 firms from 2003 to 2005. Sepehr [18] evaluated the performance of 68 corporate ICT companies from 17 industries over six years in the Tehran stock market. Most recently, the study of Lee et al. [19] that measured the efficiency and ICT ecosystem impact of the hardware and software industries in China, Japan, Korea, and the United States.

Measuring the performance of the ICT industry can share the understanding of how efficiency this industry was in the past. However, to sustain the development of this industry, the throughout evaluation of performance from the past to the future is very essential. Therefore, this study applies both GM and DEA to measure and forecast the performance efficiency of the ITC industry in Vietnam over the period 2013-2022.

DEA is a useful and popular method that is widely applied in many different research areas to evaluate and measure the performance while the grey model is the most popular used forecast model. However, these two methods are usually separately used. Some previous studies were found using both DEA and GM in evaluating performance efficiency, such as the study of Wang et al. [20] using DEA MPI and GM to measure and forecast the productivity the Vietnamese plastic industry. The study of Wang et al. [21] applied GM to DEA to access the performance of hydropower industry, and the study of Nguyen et al. [22] employed DEA and GM to evaluate the past-to-future performance 
of Indian electricity industry. The study of Wang et al. [23] applied DEA and GM to evaluate the productivity of the Vietnamese agroforest industry.

\section{Materials and Methods}

\subsection{Grey Model GM $(1,1)$}

In recent years, many researchers have applied the grey prediction model and brought great success in research in many applications, including many different areas.

The GM $(1,1)$ model is the most popular forecast model that is used by scientists in their studies. The reason is that a part of it delivers a relatively high predictive rate while requiring a small amount of input data (at least 4) in part that is suitable for almost all fields and different areas.

In this study, because the period of past data collection is only five years, the selection of this model to predict future results is perfectly appropriate.

GM $(1,1)$ represents the time-series prediction model in the first order of placing a variable [24]. The model structure of GM $(1,1)$ is described, as follows:

Denote the original string as:

$$
x^{(*)}=\left\{x^{(*)}(1), x^{(*)}(2), \ldots, x^{(*)}(n)\right\} \mathrm{n} \geq 4
$$

The one-time accumulated generating operation (1-AGO) of the original sequence $x^{(*)}$ is defined as:

$$
x^{(1)}=\left\{x^{(1)}(1), x^{(1)}(2), \ldots, x^{(1)}(n)\right\} \mathrm{n} \geq 4
$$

where

$$
x^{(*)}(1)=x^{(1)}(1) \text { and } x^{(1)}(t)=\sum_{j=1}^{t} x^{(*)}(j)(t=2,3,4, \ldots, n)
$$

Establishing a first-order differential equation with one variable is expressed, as follows:

$$
\frac{d x^{(1)}(t)}{d t}+u x^{(1)} t=v
$$

where $\mathrm{u}$ is the developing coefficient and $\mathrm{v}$ are the grey input coefficient. Using the least- squares method to determine the $\mathrm{u}, \mathrm{v}$ as the following:

$$
[u, v]^{T}=\left(D^{T} D\right)^{1} D^{T} Y
$$

where,

$$
\mathrm{D}=\left[\begin{array}{cc}
-\frac{x^{(1)}(1)+x^{(1)}(2)}{2} & 1 \\
-\frac{x^{(1)}(2)+x^{(1)}(3)}{2} & 1 \\
\vdots & \\
-\frac{x^{(1)}(n-1)+x^{(1)}(n)}{2} & 1
\end{array}\right]
$$

and

$$
\mathrm{Y}=\left[x^{(*)}(2), x^{(*)}(3), \ldots \ldots, x^{(*)}(n)\right]^{T}
$$

According to (2.4), the solution of $x^{(1)}(t)$ at time $t$ is as follows:

$$
\hat{x}^{(1)}(t+1)=\left[x^{(*)}(1)-\frac{v}{u}\right] e^{u t}+\frac{v}{u}
$$

We acquire $\hat{x}^{(1)}$ from $(2.8)$, the time response function of the GM $(1,1)$ is given by:

$$
\hat{x}^{(*)}=\left\{\hat{x}^{(*)}(1), \hat{x}^{(*)}(2), \ldots, \hat{x}^{(*)}(n)\right\}
$$


where

$$
\hat{x}^{(*)}(1)=\hat{x}^{(1)}(1)
$$

and

$$
\hat{x}^{(*)}(t)=\hat{x}^{(1)}(t)-\hat{x}^{(1)}(t-1)(\mathrm{t}=2,3 \ldots, \mathrm{n})
$$

\subsection{DEA Super-SBM Model}

After collecting and analyzing the results of the previous paper, Tone [25] has introduced and presented super-SBM model giving the principles of the super-efficiency score and non-radial measurement score. To be more precise, the Super-SBM model deals with input and output of many decision-making units (DMUs), setting inputs $(A=a h k)$ and outputs $(B=b h k)$. A and $B$ must be positive and $\mathrm{R}+$, henceforth the production possibility is denoted, as below [21]:

$$
\begin{gathered}
P=(\mathrm{A}, \mathrm{B}) \\
\text { Subject to } \\
\mathrm{a} \geq \mathrm{A} \lambda, \quad \mathrm{b} \leq \mathrm{B} \lambda, \quad \lambda \geq 0
\end{gathered}
$$

Here, $\lambda$ is a non-negative vector in $\mathrm{R}+$.

$$
\mathrm{a}_{0}=\mathrm{A} \lambda+\mathrm{f}^{-} ; \mathrm{b}_{0}=\mathrm{B} \lambda-\mathrm{f}^{+} \operatorname{with}\left\{\lambda, \mathrm{f}^{-}, \mathrm{f}^{+} \geq 0\right\}
$$

The vectors $f^{+}$and $f^{-}$belong to $R^{+}$in order to define input excess and output shortfall with the condition $A \geq 0, \lambda \geq 0$, which satisfies $a_{0} \geq f^{-}$.

Following $f^{+}, f^{-}$and, $\rho$ is formulated, as below:

$$
\begin{gathered}
\rho=\frac{1-\frac{1}{m} \sum_{h=1}^{m} f_{h}^{-} / a_{h 0}}{1-\frac{1}{s} \sum_{h=1}^{s} f_{h}^{+} / b_{h 0}} \\
\text { Subject to } \\
0<p \leq 1
\end{gathered}
$$

The efficiency of $\left(a_{0}, b_{0}\right)$ is calculated, as following:

$$
\begin{gathered}
\operatorname{Min} \rho=\frac{1-\frac{1}{m} \sum_{h=1}^{m} f_{h}^{-} / a_{h 0}}{1-\frac{1}{s} \sum_{h=1}^{s} f_{h}^{+} / b_{h 0}} \\
\text { Subject to } \\
a_{0}=A \lambda+f^{-} ; b_{0}=B \lambda+f^{+} \\
\left\{\lambda, f^{-}, f^{+} \geq 0\right\}
\end{gathered}
$$

$\rho^{*}, \lambda^{*}, f^{-*}, f^{+*}$ is the optimal solution set up for SBM model.

Based on the optimal solution, under the condition $\rho^{*}=1, f^{-*}=0, f^{+*}=0$, and there is no input excess along with no shortfall output in any optimal solution, the DMU is defined as the SBM model efficiency when it is based on the optimal solution.

$$
\begin{gathered}
\min \delta=\frac{\frac{1}{m} \sum_{h=1}^{m} \bar{a}_{h / a_{h 0}}}{\frac{1}{s} \sum_{h=1}^{f} \bar{b}_{h / b_{h 0}}} \\
\text { Subject to } \\
\bar{a} \geq \sum_{k=1, \neq 0}^{n} \lambda_{k} a_{k}, \bar{b} \leq \sum_{k=1, \neq 0}^{n} \lambda_{k} b_{k}
\end{gathered}
$$

When the output $r$ has no position, it is denoted as $\overline{b_{r}^{+}}=b_{r}^{+}=1$. Tone described the super-SBM model, as follows:

$$
\min \delta=\frac{1}{\frac{1}{s} \sum_{r=1}^{f} \overline{b_{r} / b_{r 0}}}
$$


whereas

$$
\begin{gathered}
\bar{a} \geq \sum_{k=1, \neq 0}^{n} \lambda_{k} a_{k}, \bar{b} \geq \sum_{k=1, \neq 0}^{n} \lambda_{k} b_{k} \\
\left\{\bar{a}=a_{0} ; 0 \leq \bar{b} \leq b_{0} ; \lambda \geq 0\right\}
\end{gathered}
$$

\subsection{DEA Malmquist Model}

Besides calculating technical efficiency at a given time, calculating efficiency over time is equally important. The comparison of efficiency levels between different time periods helps researchers to have a clearer view of the changes in efficiency over time, from which evaluating measuring how these changes affect efficiency, as well as partly predicting the fluctuations of efficiency in the future.

In the DEA method, the estimation of technical efficiency is done based on a defined frontier, and therefore, it is complex to compare the efficiency between two different time periods based on two different frontiers. However, the problem becomes simpler with the help of distance functions. Fare et al. [26] provide a model to determine the change in total factor productivity (TFP) over time, in which any decision-making unit (DMU) will be studied at two different time periods $\mathrm{t}$ and $\mathrm{t}+1$ (corresponding to two different frontiers at time period $t$ and $t+1$ ) and then compare the change in the combined total factor productivity of that DMU [22].

According to Fare [26], the TFP that was obtained by DEA, called Malmquist Productivity Index (MPI). MPI index of each observation corresponds to the frontier at each period of a certain group of K defined at the technical level in the period $t$, as follows.

$$
\begin{gathered}
M P I=\frac{\delta^{t+1}\left(\left(x_{0}, y_{0}\right)^{t+1}\right)}{\delta^{t}\left(\left(x_{0}, y_{0}\right)^{t}\right)} \times\left[\frac{\delta^{t}\left(\left(x_{0}, y_{0}\right)^{t}\right)}{\delta^{t+1}\left(\left(x_{0}, y_{0}\right)^{t}\right)} \times \frac{\delta^{t}\left(\left(x_{0}, y_{0}\right)^{t+1}\right)}{\delta^{t+1}\left(\left(x_{0}, y_{0}\right)^{t}\right)}\right]^{1 / 2} \\
=\left[\frac{\delta^{t}\left(\left(x_{0}, y_{0}\right)^{t+1}\right)}{\delta^{t}\left(\left(x_{0}, y_{0}\right)^{t}\right)} \times \frac{\delta^{t+1}\left(\left(x_{0}, y_{0}\right)^{t+1}\right)}{\delta^{t+1}\left(\left(x_{0}, y_{0}\right)^{t}\right)}\right]^{1 / 2}
\end{gathered}
$$

According to Fare [26] the change of TFP can be obtained by the efficiency change and technical change and measured as below formula:

$$
\mathrm{TFPCH}=\mathrm{EFCH} * \mathrm{TECHCH}
$$

TFPCH: total factor productivity change (MPI)

EFCH: efficiency change (catch-up)

TECHCH: technical change (frontier-shift)

In which:

$$
\mathrm{EFCH}=\frac{\delta^{t+1}\left(\left(x_{0,} y_{0}\right)^{t+1}\right)}{\delta^{t}\left(\left(x_{0}, y_{0}\right)^{t}\right)}
$$

And

$$
\mathrm{TECHCH}=\left[\frac{\delta^{t}\left(\left(x_{0}, y_{0}\right)^{t}\right)}{\delta^{t+1}\left(\left(x_{0}, y_{0}\right)^{t}\right)} \times \frac{\delta^{t}\left(\left(x_{0}, y_{0}\right)^{t+1}\right)}{\delta^{t+1}\left(\left(x_{0}, y_{0}\right)^{t}\right)}\right]
$$

Thus, when TFPCH $>1$, the total factor productivity of considering DMU has increased at time $\mathrm{t}+1$ compared to time $\mathrm{t}$. TFPCH $<1$ indicates the decrease in total factor productivity at time $\mathrm{t}+1$ as compared to time $t$. TFPCH $=1$ means the total factor productivity remains unchanged. 


\section{Empirical Results}

\subsection{Efficiency Evaluation over the Period 2013-2017}

In this study, the Super-SBM model was used to evaluate the efficiency of 24 ICT companies in Vietnam during 2013-2022 with three selected inputs (Cost of goods sold, Operation cost, and Total assets) and two outputs (Net sale and Profit afte-tax). This study uses DEA-Solver Pro V13.2 to run DEA Super-SBM. Before obtaining the efficiency scores, the authors would like to test the correlation between inputs and outputs as when employing DEA approach, the researcher concerns ensuring not merely that the relationship between input and output indicators is isotonic, but also that the linear relation determines an efficiency measure of position relative to the frontier toward each DMU. In this paper, a Pearson correlation is conducted to define the level of alignment between two variables, whereas a higher correlation coefficient implies a closer relation and vice versa.

The results of correlation testing presented at Table 1 indicate that there exists the linear correlation between inputs and output with the positive associations. Thus, the correlation correlates well with the prerequisite condition of the DEA model.

Table 1. Correlation between variables (2017).

\begin{tabular}{cccccc}
\hline Year 2017 & Cost of Goods Sold & Operation Cost & Total Asset & Net Sales & Profit after Tax \\
\hline Cost of Goods sold & 1 & 0.9606 & 0.9659 & 0.9973 & 0.9840 \\
Operation Cost & 0.9606 & 1 & 0.9885 & 0.9450 & 0.9918 \\
Total Asset & 0.9659 & 0.9885 & 1 & 0.9524 & 0.9839 \\
Net sales & 0.9973 & 0.9450 & 0.9524 & 1 & 0.9735 \\
Profit after Tax & 0.9840 & 0.9918 & 0.9839 & 0.9735 & 1 \\
\hline
\end{tabular}

After making sure of the correlation between inputs and outputs, DEA Super-SBM is applied to obtain the efficiency scores of 24 ICT companies over the period 2013-2017 and Table 2 reports the obtained results.

Table 2. The efficiency of ICT companies (2013-2017).

\begin{tabular}{llllllc}
\hline DMU & $\mathbf{2 0 1 3}$ & $\mathbf{2 0 1 4}$ & $\mathbf{2 0 1 5}$ & $\mathbf{2 0 1 6}$ & $\mathbf{2 0 1 7}$ & Average \\
\hline DMU1 & 1.000 & 1.000 & 1.000 & 1.000 & 1.000 & 1.000 \\
DMU2 & 2.244 & 1.875 & 1.787 & 1.714 & 1.720 & 1.868 \\
DMU3 & 3.288 & 2.028 & 0.729 & 0.532 & 0.554 & 1.426 \\
DMU4 & 0.743 & 0.901 & 0.935 & 0.887 & 1.004 & 0.894 \\
DMU5 & 1.072 & 1.197 & 1.099 & 1.233 & 1.091 & 1.138 \\
DMU6 & 0.641 & 1.360 & 1.046 & 0.891 & 0.752 & 0.938 \\
DMU7 & 0.674 & 0.691 & 0.736 & 0.715 & 0.758 & 0.715 \\
DMU8 & 0.492 & 0.477 & 0.526 & 1.282 & 1.402 & 0.836 \\
DMU9 & 1.202 & 1.150 & 1.325 & 1.303 & 1.164 & 1.229 \\
DMU10 & 4.613 & 2.766 & 3.326 & 8.926 & 4.220 & 4.770 \\
DMU11 & 0.772 & 1.082 & 1.044 & 1.327 & 1.287 & 1.102 \\
DMU12 & 2.323 & 1.105 & 0.997 & 0.839 & 0.935 & 1.240 \\
DMU13 & 0.947 & 0.951 & 0.954 & 0.903 & 0.898 & 0.931 \\
DMU14 & 0.839 & 0.921 & 1.061 & 0.851 & 0.862 & 0.907 \\
DMU15 & 0.674 & 0.700 & 2.082 & 1.316 & 2.296 & 1.414 \\
DMU16 & 0.691 & 0.725 & 0.722 & 0.716 & 0.723 & 0.715 \\
DMU17 & 0.599 & 0.689 & 0.719 & 0.793 & 0.770 & 0.714 \\
DMU18 & 0.766 & 0.759 & 0.751 & 0.777 & 0.835 & 0.777 \\
DMU19 & 0.708 & 1.514 & 1.180 & 1.048 & 1.571 & 1.204 \\
DMU20 & 0.787 & 0.835 & 0.824 & 0.736 & 0.893 & 0.815 \\
DMU21 & 1.188 & 1.312 & 1.305 & 1.425 & 1.474 & 1.341 \\
DMU22 & 0.855 & 0.906 & 0.854 & 0.923 & 1.003 & 0.908 \\
DMU23 & 0.912 & 1.845 & 1.319 & 1.155 & 1.136 & 1.273 \\
DMU24 & 0.872 & 0.835 & 0.783 & 0.760 & 0.818 & 0.814 \\
Average & 1.204 & 1.151 & 1.129 & 1.335 & 1.215 & 1.207 \\
\hline
\end{tabular}


On average, of 24 ICT companies, 12 companies were found to be inefficient with the corresponding efficiency score lower than 1 . For these inefficient, the average score ranges from 0.714 to 0.938 , with the inefficiency in performance indicating the unbalance between inputs and outputs. On the other hand, the haft of selected companies showed better performance with the corresponding score being equal and higher than 1. The highest score during 2013-2017 was 8.926 of DMU10 in 2016, which leads to the highest average score for the whole observed period was 4.77 .

According to data in Table 2, it is clear to note that the distance from the lowest average score (0.714) to the highest one (4.77) is notable, which indicates an extreme difference in controlling the inputs and outputs of these companies. Additionally, this also implies the high competitiveness in the ICT industry in Vietnam.

By looking at the average score of each year, it is noted that the average scores slightly fluctuated over period 2013-2017. Particularly, the average score decreased from 1.204 in 2013 to 1.129 in 2015 the rapidly recovered in 2016 with a score of 1.335, and then slightly went down in 2017. During 2016, the average score reached the highest thanks to the extremely high score of DMU 10 caused by the rapid growth of net sale revenue.

\subsection{Forecasting Value of Inputs and Outputs Over the Period 2018-2022}

To predict the realistic input and output factors of 24 companies in Vietnam across the period 2018-2022, the GM $(1,1)$ model is applied. Historical data of each DMU from 2013 to 2017 are used as the base to generate forecasting data for the year 2018 to 2022, respectively.

After conducting the G $(1,1)$ model, the forecasted data for 24 DMUs for future period 2018-2022 are obtained. However, due to limited space, we only give the result of the sample year 2018 in Table 3, below. Forecast inputs and outputs for period 2018-2022 will then be used to obtain the efficiency score for the future period.

Table 3. Forecasted value of inputs and outputs in 2018.

\begin{tabular}{|c|c|c|c|c|c|}
\hline DMUs & $\begin{array}{l}\text { (I) Cost of } \\
\text { Goods sold }\end{array}$ & (I) Operation Cost & (I) Total Asset & (O) Profit after Tax & (O) Net Sales \\
\hline DMU1 & $35,545,961$ & $8,458,393$ & $28,522,048$ & $4,684,182$ & $46,638,793$ \\
\hline DMU2 & $4,581,873$ & $3,231,391$ & $10,003,021$ & $1,233,597$ & $2,214,997$ \\
\hline DMU3 & $2,144,791$ & 400,159 & $4,644,791$ & 111,446 & $2,307,162$ \\
\hline DMU4 & $4,902,785$ & 568,980 & $3,718,693$ & 345,664 & $5,728,607$ \\
\hline DMU5 & $1,732,966$ & 216,599 & 483,538 & 44,577 & $1,945,449$ \\
\hline DMU6 & 793,632 & 150,645 & $1,093,449$ & 63,356 & $1,003,022$ \\
\hline DMU7 & $1,898,474$ & 234,635 & $2,160,973$ & 40,518 & $2,179,788$ \\
\hline DMU8 & 757,294 & 155,604 & $1,858,850$ & 137,449 & $1,161,408$ \\
\hline DMU9 & 222,194 & 71,249 & 182,494 & 35,734 & 330,740 \\
\hline DMU10 & $6,582,050$ & 84,239 & 919,411 & 288,970 & $6,625,740$ \\
\hline DMU11 & 513,322 & 108,562 & 691,340 & 101,177 & 709,044 \\
\hline DMU12 & $1,763,870$ & 156,816 & $1,763,612$ & 16,068 & $1,913,734$ \\
\hline DMU13 & 318,597 & 79,747 & 246,659 & 13,297 & 411,215 \\
\hline DMU14 & 640,209 & 41,366 & 564,976 & 21,065 & 685,160 \\
\hline DMU15 & 21,761 & 2379 & 168,088 & 2,647 & 27,085 \\
\hline DMU16 & 347,595 & 47,240 & 523,858 & 13,047 & 397,469 \\
\hline DMU17 & 132,776 & 42,199 & 188,963 & 4500 & 175,565 \\
\hline DMU18 & 873,910 & 98,506 & 364,820 & 11,964 & 981,160 \\
\hline DMU19 & 36,928 & 2371 & 140,121 & 2,552 & 40,824 \\
\hline DMU20 & 401,577 & 30,792 & 315,140 & 7384 & 436,679 \\
\hline DMU21 & 246,488 & 115,840 & 127,236 & 10,585 & 373,222 \\
\hline DMU22 & 400,952 & 18,824 & 247,987 & 10,337 & 427,404 \\
\hline DMU23 & 60,262 & 6937 & 123,085 & 1,590 & 69,728 \\
\hline DMU24 & 480,974 & 45,792 & 443,728 & 9641 & 538,153 \\
\hline
\end{tabular}

Forecasting always comes with error; therefore; the accuracy of the forecast model is a big concern. Thus, before using the forecasted inputs and outputs to obtain the efficiency score during period $2018-2022$, it is necessary to test the accuracy of GM $(1,1)$ model. 
In this study, the simple but widely used testing method called mean absolute percent error (MAPE) is applied to test the error percentage of the forecast model.

MAPE is the average absolute percent error that measures the accuracy in a fitted time series value in statistics, specifically trending.

$$
M A P E=\frac{1}{n} \sum \frac{\mid \text { Actual }- \text { Forecast } \mid}{\text { Actual }} \times 100 \%
$$

The parameters of MAPE state the forecasting ability as following:

MAPE $<10 \%$ represents Excellent

$10 \%<$ MAPE $<20 \%$ is Good.

$20 \%<$ MAPE $<50 \%$ "Reasonable"

MAPE $>50 \%$ "Poor

Table 4 displays the result of MAPE. As the MAPE values obtained are, mostly, smaller than $10 \%$, it confirms that the GM $(1,1)$ provides a good prediction accuracy in this research.

Table 4. Average MAPE of all DMUs.

\begin{tabular}{cccccccc}
\hline DMU & MAPE & DMU & MAPE & DMU & MAPE & DMU & MAPE \\
\hline DMU1 & $2.76 \%$ & DMU7 & $16.31 \%$ & DMU13 & $5.2 \%$ & DMU19 & $13.72 \%$ \\
DMU2 & $3.19 \%$ & DMU8 & $18.26 \%$ & DMU14 & $12.63 \%$ & DMU20 & $9.45 \%$ \\
DMU3 & $12.39 \%$ & DMU9 & $2.33 \%$ & DMU15 & $14.44 \%$ & DMU21 & $1.78 \%$ \\
DMU4 & $3 \%$ & DMU10 & $3.8 \%$ & DMU16 & $4.13 \%$ & DMU22 & $5.65 \%$ \\
DMU5 & $5.97 \%$ & DMU11 & $17.64 \%$ & DMU17 & $6.09 \%$ & DMU23 & $14.74 \%$ \\
DMU6 & $11.86 \%$ & DMU12 & $24.21 \%$ & DMU18 & $6.36 \%$ & DMU24 & $12.33 \%$ \\
\hline
\end{tabular}

\subsection{Efficiency Evaluation over the Period 2018-2022}

In this stage, the forecasted data of inputs and outputs are used to obtain the efficiency scores over the future period 2018-2022. Table 5 presents the efficiency scores of 24 ICT companies during 2018-2022.

Table 5. The efficient and inefficient index of ICT companies (2018-2022).

\begin{tabular}{ccccccc}
\hline DMU & $\mathbf{2 0 1 8}$ & $\mathbf{2 0 1 9}$ & $\mathbf{2 0 2 0}$ & $\mathbf{2 0 2 1}$ & $\mathbf{2 0 2 2}$ & Average \\
\hline DMU1 & 1.000 & 1.000 & 1.000 & 1.000 & 1.000 & 1.000 \\
DMU2 & 1.668 & 1.630 & 1.593 & 0.345 & 0.150 & 1.077 \\
DMU3 & 0.470 & 0.422 & 0.392 & 0.336 & 0.280 & 0.380 \\
DMU4 & 0.924 & 0.876 & 1.274 & 0.802 & 0.767 & 0.928 \\
DMU5 & 1.092 & 0.916 & 0.812 & 0.721 & 0.652 & 0.839 \\
DMU6 & 0.809 & 0.711 & 0.621 & 0.559 & 0.516 & 0.643 \\
DMU7 & 0.729 & 0.624 & 0.550 & 0.499 & 0.462 & 0.573 \\
DMU8 & 1.350 & 1.739 & 1.810 & 1.678 & 1.525 & 1.620 \\
DMU9 & 1.272 & 1.265 & 1.134 & 1.046 & 1.052 & 1.154 \\
DMU10 & 6.137 & 7.163 & 9.110 & 10.764 & 11.265 & 8.888 \\
DMU11 & 1.334 & 0.960 & 0.727 & 0.636 & 0.568 & 0.845 \\
DMU12 & 0.849 & 0.769 & 0.676 & 0.607 & 0.523 & 0.685 \\
DMU13 & 0.846 & 0.802 & 0.762 & 0.667 & 0.584 & 0.732 \\
DMU14 & 0.733 & 0.549 & 0.500 & 0.490 & 0.493 & 0.553 \\
DMU15 & 1.760 & 1.940 & 2.112 & 2.158 & 2.210 & 2.036 \\
DMU16 & 0.691 & 0.622 & 0.556 & 0.508 & 0.474 & 0.570 \\
DMU17 & 0.816 & 0.845 & 0.853 & 0.917 & 1.072 & 0.901 \\
DMU18 & 0.838 & 0.868 & 0.868 & 0.849 & 0.813 & 0.847 \\
DMU19 & 1.098 & 1.069 & 1.064 & 1.062 & 1.059 & 1.071 \\
DMU20 & 0.801 & 0.745 & 0.678 & 0.631 & 0.596 & 0.690 \\
DMU21 & 1.572 & 1.659 & 1.706 & 1.725 & 1.686 & 1.670 \\
DMU22 & 0.930 & 0.808 & 0.707 & 0.669 & 0.673 & 0.757 \\
DMU23 & 1.053 & 0.985 & 0.808 & 0.733 & 0.670 & 0.849 \\
DMU24 & 0.775 & 0.716 & 0.634 & 0.573 & 0.526 & 0.645 \\
Average & 1.231 & 1.237 & 1.289 & 1.249 & 1.234 & 1.248 \\
\hline
\end{tabular}


According to data in Table 5, the average score of selected DMUs ranged from the lowest 1.231 to the highest 1.289. As observed, in the future, the ICT industry in Vietnam will perform more effectively than in the past period 2013-2017 proved by the higher average score. During the past period, the average score of 24 companies was 1.207 while this of the future years will be 1.248. However, notably, the number of efficient DMU will be significantly decreased. In the past, there were 12 out of total 24 DMUs found to be efficient, but this number will reduce to 8 over the period 2018-2022, which implies that more than half of ICT companies will operate ineffectively and perform poorly in terms of efficiency.

Five DMUs that used to be efficient during 2013-2017 will turn into inefficient over period 2018-2022 (DMU3, DMU5, DMU11, DMU12 and DMU13), while 1 DMU that had the score lower than 1 during 2013-2017 (0.836) reached the score of 1.62 during 2018-2022. The decrease in the number of efficient DMU that was probably caused by the current favorable conditions to develop ICT industry in Vietnam but these conditions will not that much in the future, which force ICT companies to operate in the more competitive environment. Without the favorable conditions and policies to develop ICT industry in the future, only the company presenting well-managed inputs and outputs can effectively perform in this high competitiveness.

Moreover, it is observed that, during 2018-2022, the lowest average score will be 0.38, while the highest will be 8.89 , which indicated the larger distance between different DMU. This finding raises an alert to the DMUs which poorly perform in the industry as by using the same level of given inputs other companies can generate a much higher level of outputs than them or by using far fewer inputs to generate the same level of outputs.

\subsection{Malmquist Productivity Index}

Malmquist productivity index (MPI) was used to evaluate the productivity change of a company between different periods. The index is defined as the combination of Catch-up representing the change in efficiency and Frontier-shift indicating the technological changes. In order to evaluate the change of the productivity, efficiency, and technology of 24 companies from 2013 to 2022, this research used DEA-Solver Pro V13.2 to analyze.

Firstly, the efficiency change is examined with results shown in Table 6. It is observed that each DMU experienced the change in efficiency year by year with the great fluctuation of average catch-up scores in the early period, and then slightly increased in later years. As observed, all the DMUs experience both improvements and regress in efficiency with the corresponding score higher and lower than 1 , respectively.

Averagely, there are six companies witness the efficiency improvement with the catch-up score above 1 during 2013-2022. In summary, during 2013-2022, for the industry average, efficiency suffers a loss of $2 \%$ with a fluctuation during 2013-2017, and then suffers a continual decline from 2018 to 2022, which might be due to the pessimism in forecasted data.

Secondly, the technical change that captures the shift in the frontier is examined. Table 7 reports the annual technical progress or regress of all DMUs from 2013 to 2022. The results in Table 7 indicates the progress in technical change with the average score for the period 2013-2022 greater than 1 . As can be seen from Table 7, the results indicate that technical change increased at most of the sample periods except the regress during 2013-2014 and 2016-2017. However, the fall in technical change score is insignificant, roughly 3\%. Notably, only DMU21 experiences the increase over the period 2013-2018, while other companies showed averaged progress but fluctuation during 2013-2018.

Finally, after getting the results of catch-up and frontier-shift, the MPI is applied to evaluate the total productivity change of each DMU in deferent periods. Table 8 presents the results of MPI change of all 24 companies during 2013-2022. The results of MPI reveal that the as a whole, the productivity of these 24 ICT companies increases over the previous years and they are moving along the best production frontier. 
Table 6. The Catch-up efficiency change.

\begin{tabular}{|c|c|c|c|c|c|c|c|c|c|c|}
\hline Catch-up & 2013-2014 & 2014-2015 & 2015-2016 & 2016-2017 & $2017-2018$ & 2018-2019 & $2019-2020$ & 2020-2021 & $2021-2022$ & Average \\
\hline DMU1 & 1.00 & 0.91 & 0.92 & 1.08 & 1.00 & 0.96 & 0.88 & 0.85 & 0.88 & 0.94 \\
\hline DMU2 & 0.82 & 0.92 & 1.04 & 0.84 & 1.06 & 0.61 & 0.58 & 0.59 & 0.60 & 0.78 \\
\hline DMU3 & 0.48 & 0.85 & 0.78 & 1.03 & 0.86 & 0.89 & 0.93 & 0.87 & 0.83 & 0.83 \\
\hline DMU4 & 1.09 & 1.06 & 0.94 & 1.08 & 0.98 & 0.90 & 0.85 & 0.88 & 0.90 & 0.97 \\
\hline DMU5 & 1.11 & 0.94 & 1.01 & 0.89 & 0.96 & 0.95 & 0.93 & 0.84 & 0.88 & 0.95 \\
\hline DMU6 & 1.91 & 0.70 & 0.96 & 0.91 & 1.03 & 0.90 & 0.86 & 0.89 & 0.91 & 1.01 \\
\hline DMU7 & 1.02 & 1.06 & 0.99 & 1.03 & 0.97 & 0.87 & 0.88 & 0.91 & 0.93 & 0.96 \\
\hline DMU8 & 0.97 & 1.12 & 1.37 & 1.40 & 1.04 & 1.21 & 1.20 & 0.99 & 0.93 & 1.14 \\
\hline DMU9 & 0.99 & 1.14 & 0.91 & 0.92 & 1.04 & 0.95 & 0.87 & 0.78 & 0.85 & 0.94 \\
\hline DMU10 & 0.58 & 1.09 & 2.17 & 0.77 & 0.94 & 1.19 & 1.01 & 0.99 & 0.97 & 1.08 \\
\hline DMU11 & 1.40 & 0.90 & 1.33 & 0.98 & 1.03 & 0.73 & 0.72 & 0.86 & 0.89 & 0.98 \\
\hline DMU12 & 1.21 & 1.15 & 0.74 & 1.07 & 0.92 & 0.83 & 0.88 & 0.91 & 0.86 & 0.95 \\
\hline DMU13 & 1.03 & 0.99 & 0.91 & 1.05 & 0.95 & 0.97 & 0.85 & 0.84 & 0.88 & 0.94 \\
\hline DMU14 & 1.06 & 1.07 & 0.88 & 1.15 & 0.79 & 0.75 & 0.93 & 1.01 & 1.02 & 0.96 \\
\hline DMU15 & 0.95 & 3.31 & 0.33 & 1.16 & 1.52 & 0.58 & 0.89 & 0.91 & 0.91 & 1.17 \\
\hline DMU16 & 1.04 & 1.00 & 0.97 & 1.03 & 0.95 & 0.85 & 0.89 & 0.92 & 0.94 & 0.95 \\
\hline DMU17 & 1.15 & 1.04 & 1.05 & 0.97 & 1.03 & 1.00 & 0.86 & 0.88 & 0.86 & 0.98 \\
\hline DMU18 & 0.98 & 0.98 & 1.03 & 1.11 & 1.00 & 1.04 & 0.92 & 0.89 & 0.92 & 0.99 \\
\hline DMU19 & 2.07 & 0.81 & 0.58 & 1.85 & 0.58 & 0.86 & 0.89 & 0.91 & 0.93 & 1.06 \\
\hline DMU20 & 1.03 & 1.01 & 0.86 & 1.25 & 0.85 & 0.86 & 0.88 & 0.91 & 0.93 & 0.95 \\
\hline DMU21 & 1.01 & 1.01 & 1.00 & 1.02 & 1.01 & 1.01 & 1.01 & 1.00 & 0.97 & 1.01 \\
\hline DMU22 & 0.96 & 0.96 & 1.06 & 1.30 & 0.79 & 0.85 & 0.88 & 0.96 & 1.05 & 0.98 \\
\hline DMU23 & 0.95 & 1.15 & 0.99 & 0.88 & 0.99 & 0.86 & 0.89 & 0.91 & 0.93 & 0.95 \\
\hline DMU24 & 0.95 & 0.96 & 0.94 & 1.09 & 0.95 & 0.87 & 0.87 & 0.90 & 0.92 & 0.94 \\
\hline Average & 1.07 & 1.09 & 0.99 & 1.08 & 0.97 & 0.90 & 0.89 & 0.89 & 0.90 & 0.98 \\
\hline
\end{tabular}


Table 7. The Frontier-shift change.

\begin{tabular}{|c|c|c|c|c|c|c|c|c|c|c|}
\hline Frontier & $2013-2014$ & 2014-2015 & 2015-2016 & 2016-2017 & $2017-2018$ & 2018-2019 & 2019-2020 & $2020-2021$ & $2021-2022$ & Average \\
\hline DMU1 & 0.98 & 1.08 & 1.05 & 1.03 & 0.99 & 1.09 & 1.27 & 1.21 & 1.16 & 1.10 \\
\hline DMU2 & 0.87 & 1.00 & 0.96 & 1.06 & 0.93 & 1.23 & 1.65 & 1.62 & 1.60 & 1.21 \\
\hline DMU3 & 1.04 & 1.09 & 1.04 & 0.92 & 1.05 & 1.06 & 1.04 & 1.10 & 1.15 & 1.05 \\
\hline DMU4 & 1.00 & 0.99 & 1.04 & 0.93 & 1.09 & 1.11 & 1.17 & 1.13 & 1.11 & 1.06 \\
\hline DMU5 & 0.98 & 1.04 & 1.04 & 0.98 & 1.04 & 1.01 & 1.03 & 1.14 & 1.11 & 1.04 \\
\hline DMU6 & 0.96 & 1.15 & 0.94 & 0.93 & 1.03 & 1.11 & 1.16 & 1.12 & 1.09 & 1.05 \\
\hline DMU7 & 0.99 & 0.99 & 1.03 & 0.94 & 1.04 & 1.14 & 1.13 & 1.10 & 1.08 & 1.05 \\
\hline DMU8 & 1.00 & 1.03 & 1.02 & 0.87 & 1.01 & 1.18 & 1.34 & 1.47 & 1.46 & 1.15 \\
\hline DMU9 & 0.97 & 0.98 & 1.06 & 1.01 & 1.00 & 1.03 & 1.13 & 1.29 & 1.18 & 1.07 \\
\hline DMU10 & 0.86 & 1.04 & 1.00 & 1.48 & 0.98 & 1.25 & 1.37 & 1.40 & 1.42 & 1.20 \\
\hline DMU11 & 0.97 & 1.11 & 0.91 & 1.06 & 0.98 & 1.34 & 1.46 & 1.17 & 1.14 & 1.13 \\
\hline DMU12 & 1.00 & 1.06 & 1.04 & 0.95 & 1.03 & 1.14 & 1.10 & 1.07 & 1.13 & 1.06 \\
\hline DMU13 & 1.00 & 1.03 & 1.02 & 0.95 & 1.03 & 1.01 & 1.16 & 1.16 & 1.12 & 1.05 \\
\hline DMU14 & 0.99 & 1.05 & 1.04 & 0.89 & 1.11 & 1.06 & 1.03 & 1.04 & 1.05 & 1.03 \\
\hline DMU15 & 0.97 & 1.21 & 0.88 & 0.92 & 1.07 & 1.70 & 1.13 & 1.10 & 1.11 & 1.12 \\
\hline DMU16 & 0.99 & 0.99 & 1.02 & 0.94 & 1.04 & 1.14 & 1.10 & 1.08 & 1.06 & 1.04 \\
\hline DMU17 & 0.98 & 0.99 & 1.02 & 0.96 & 1.03 & 1.02 & 1.17 & 1.15 & 1.18 & 1.05 \\
\hline DMU18 & 0.98 & 1.01 & 1.06 & 0.90 & 1.05 & 1.00 & 1.14 & 1.20 & 1.14 & 1.06 \\
\hline DMU19 & 0.86 & 1.54 & 0.79 & 1.08 & 1.00 & 1.12 & 1.09 & 1.07 & 1.05 & 1.07 \\
\hline DMU20 & 0.98 & 1.00 & 1.05 & 0.88 & 1.08 & 1.13 & 1.10 & 1.08 & 1.06 & 1.04 \\
\hline DMU21 & 1.02 & 1.02 & 1.01 & 1.01 & 1.01 & 1.01 & 1.01 & 1.02 & 1.05 & 1.02 \\
\hline DMU22 & 1.00 & 1.00 & 1.04 & 0.79 & 1.24 & 1.11 & 1.05 & 1.05 & 1.06 & 1.04 \\
\hline DMU23 & 1.00 & 1.01 & 1.03 & 0.88 & 1.12 & 1.14 & 1.11 & 1.08 & 1.06 & 1.05 \\
\hline DMU24 & 0.97 & 1.00 & 1.06 & 0.91 & 1.05 & 1.14 & 1.13 & 1.10 & 1.08 & 1.05 \\
\hline Average & 0.97 & 1.06 & 1.01 & 0.97 & 1.04 & 1.14 & 1.17 & 1.17 & 1.15 & 1.07 \\
\hline
\end{tabular}


Table 8. The Total productivity change-(MPI).

\begin{tabular}{|c|c|c|c|c|c|c|c|c|c|c|}
\hline Malmquist & 2013-2014 & 2014-2015 & 2015-2016 & 2016-2017 & $2017-2018$ & 2018-2019 & 2019-2020 & 2020-2021 & $2021-2022$ & Average \\
\hline DMU1 & 0.97 & 0.98 & 0.96 & 1.12 & 1.00 & 1.04 & 1.13 & 1.03 & 1.02 & 1.03 \\
\hline DMU2 & 0.72 & 0.92 & 1.00 & 0.89 & 0.98 & 0.75 & 0.96 & 0.96 & 0.96 & 0.90 \\
\hline DMU3 & 0.50 & 0.93 & 0.81 & 0.95 & 0.90 & 0.94 & 0.96 & 0.96 & 0.95 & 0.88 \\
\hline DMU4 & 1.10 & 1.05 & 0.98 & 1.01 & 1.06 & 1.01 & 1.00 & 1.00 & 1.00 & 1.02 \\
\hline DMU5 & 1.09 & 0.98 & 1.05 & 0.87 & 1.00 & 0.96 & 0.96 & 0.97 & 0.98 & 0.98 \\
\hline DMU6 & 1.82 & 0.81 & 0.90 & 0.85 & 1.06 & 1.00 & 1.00 & 1.00 & 1.00 & 1.05 \\
\hline DMU7 & 1.01 & 1.05 & 1.02 & 0.96 & 1.01 & 0.99 & 0.99 & 1.00 & 1.00 & 1.00 \\
\hline DMU8 & 0.96 & 1.15 & 1.40 & 1.22 & 1.05 & 1.43 & 1.60 & 1.45 & 1.35 & 1.29 \\
\hline DMU9 & 0.96 & 1.11 & 0.97 & 0.93 & 1.04 & 0.99 & 0.98 & 1.01 & 1.00 & 1.00 \\
\hline DMU10 & 0.50 & 1.14 & 2.18 & 1.15 & 0.92 & 1.50 & 1.39 & 1.38 & 1.38 & 1.28 \\
\hline DMU11 & 1.36 & 1.00 & 1.21 & 1.03 & 1.01 & 0.98 & 1.05 & 1.01 & 1.01 & 1.07 \\
\hline DMU12 & 1.20 & 1.22 & 0.77 & 1.02 & 0.95 & 0.95 & 0.96 & 0.97 & 0.97 & 1.00 \\
\hline DMU13 & 1.03 & 1.02 & 0.93 & 1.00 & 0.98 & 0.98 & 0.98 & 0.98 & 0.98 & 0.99 \\
\hline DMU14 & 1.05 & 1.12 & 0.92 & 1.02 & 0.89 & 0.79 & 0.96 & 1.05 & 1.07 & 0.99 \\
\hline DMU15 & 0.92 & 4.00 & 0.29 & 1.06 & 1.64 & 0.99 & 1.01 & 1.01 & 1.01 & 1.33 \\
\hline DMU16 & 1.03 & 0.99 & 0.99 & 0.96 & 0.99 & 0.97 & 0.98 & 0.98 & 0.99 & 0.99 \\
\hline DMU17 & 1.12 & 1.03 & 1.07 & 0.93 & 1.06 & 1.02 & 1.01 & 1.02 & 1.01 & 1.03 \\
\hline DMU18 & 0.97 & 0.98 & 1.10 & 1.00 & 1.05 & 1.04 & 1.06 & 1.07 & 1.05 & 1.04 \\
\hline DMU19 & 1.77 & 1.25 & 0.46 & 2.00 & 0.57 & 0.96 & 0.97 & 0.98 & 0.98 & 1.11 \\
\hline DMU20 & 1.01 & 1.01 & 0.90 & 1.10 & 0.92 & 0.97 & 0.97 & 0.98 & 0.99 & 0.98 \\
\hline DMU21 & 1.04 & 1.04 & 1.02 & 1.03 & 1.02 & 1.02 & 1.02 & 1.02 & 1.02 & 1.02 \\
\hline DMU22 & 0.96 & 0.95 & 1.10 & 1.03 & 0.98 & 0.94 & 0.93 & 1.01 & 1.10 & 1.00 \\
\hline DMU23 & 0.94 & 1.16 & 1.02 & 0.77 & 1.11 & 0.98 & 0.99 & 0.99 & 0.99 & 0.99 \\
\hline DMU24 & 0.93 & 0.96 & 1.00 & 0.99 & 0.99 & 0.99 & 0.99 & 0.99 & 0.99 & 0.98 \\
\hline Average & 1.04 & 1.16 & 1.00 & 1.04 & 1.01 & 1.01 & 1.03 & 1.03 & 1.03 & 1.04 \\
\hline
\end{tabular}


In 2014-2015, MPI hit the highest score and it means that, in 2015, the ICT industry of Vietnam has the best productivity, besides that it is the only one year that both Catch-up and Frontier scores above 1 , which means that this year is the best productivity improvement scenario because the productivity change is associated with a positive technology shift and an improvement in technical efficiency. As we discussed before, from 2017 to 2022 the index of Catch-up scores is under 1 and Frontier-shift scores are more than 1. As defined, MPI is mixed scores from Catch-up and Frontier, so, in this case, it points out that the only reason for productivity gain is due to average technology progress. However, in this case, the technology moves from a positive shift facet towards a negative shift facet, indicating an unfavorable strategy change. Figure 1, below, shows the average mean of MIP change.

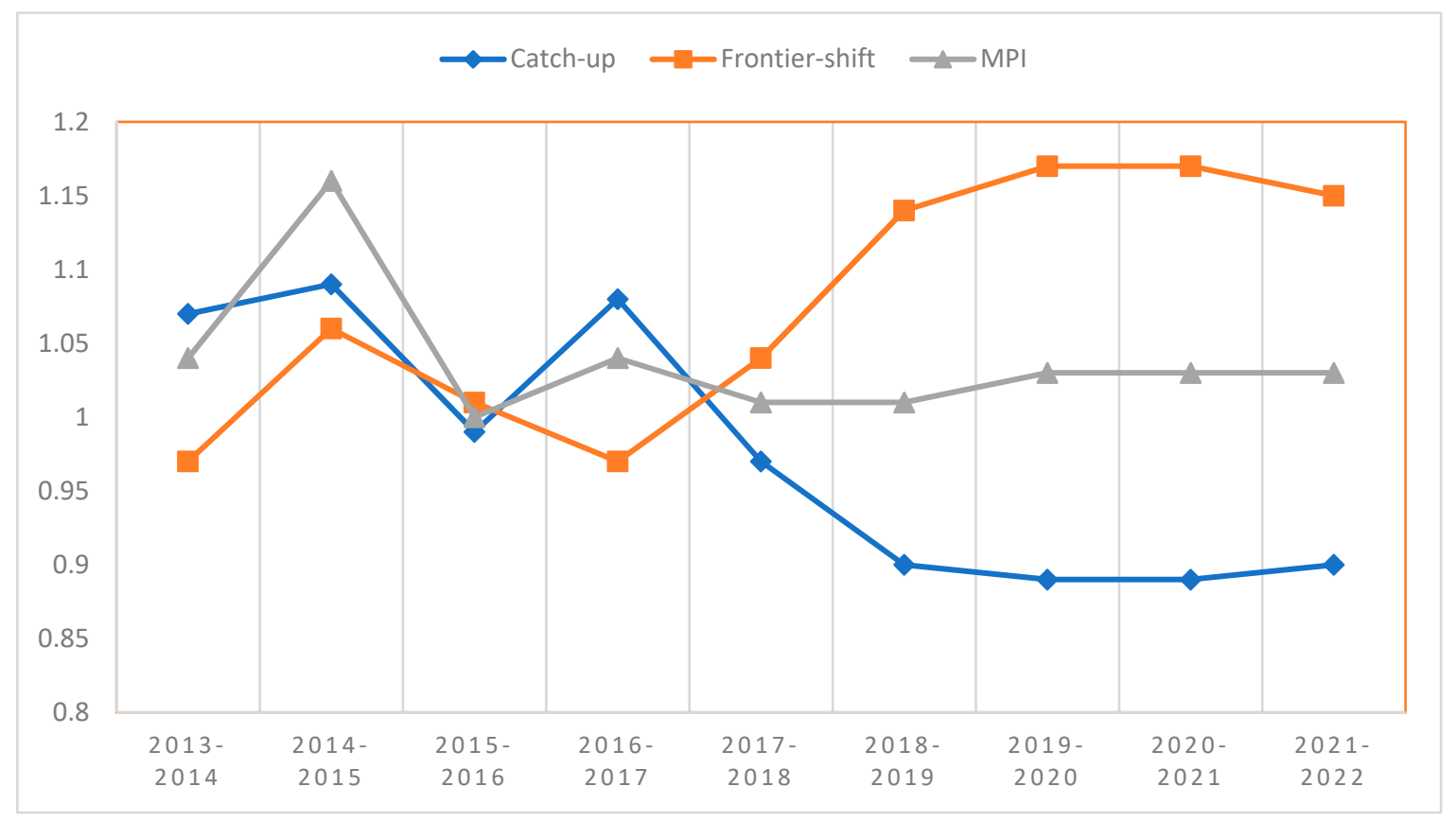

Figure 1. Average mean of MPI change of information and communication technology (ICT) industry.

\section{Discussion and Conclusions}

This study aims to examine the efficiency of Vietnamese ICT companies not only in the past period (2013-2017) but also in future periods. To do this, we applied Grey model to obtain forecasted data for period 2018-2022, and then employed the DEA approach to measure performance efficiency and efficiency improvement of 24 sample ICT companies over 2013-2022.

Firstly, DEA-super SBM was applied to obtain the score and ranking of all ICT companies in Vietnam over the past period 2013-2017. The obtained results indicated haft of selected ICT companies were inefficient and the distance from the lowest average score to the highest average score is notable, which indicates an extreme difference in controlling the inputs and outputs of these companies as well as the high competitiveness in the ICT industry in Vietnam.

Secondly, the Grey model was applied to forecast the value of inputs and outputs for the future period 2018-2022. After testing the accuracy of prediction, all the forecasted data were used to evaluate the performance of these ICT companies during 2018-2022 under Super-SBM model. The findings revealed that more than half of ICT companies would operate ineffectively and perform poorly in terms of efficiency. Additionally, the number of efficient companies will also be significantly reduced. However, despite the decrease in the number of efficient firms, the average efficiency score over period 2018-2022 will still be higher than the score of the past period 2013-2017, driven by the much better performance of one company (DMU10). The distance between the efficient one and inefficient DMU will be larger, which raises alert to the companies poorly performing in the industry. 
The Malmquist Productivity Index was employed in the next step to examine efficiency improvement. The Malmquist model's results provide insight views into the ICT industry in terms of "efficiency changes", "technological changes", and MPI. Generally, these results provide an insight view of past and future performance of ICT companies. Findings of this study reveals that the ICT industry of Vietnam always has a positive change over 2013-2022. By comparing the industry average with the results of each business, it is possible to help in recognizing the weakness as well as strength of the ICT industry, which help to make suitable strategies.

Results indicators show that the ICT industry in Vietnam in general has always been effective over the years, which strongly confirm that the ICT industry is worth the investment. However, individual examining the performance of each company, the results reveals that the number of inefficient companies in each year is always higher than efficient ones. This result implies that the industry will have much more potential for growth if it is possible to improve the number of efficient businesses. By comparing the industry average with the results of each business, helping businesses to realize where they are in the market, recognizing the inefficiencies of businesses also help to provide an option for investors. Investors can use this approach to discover good companies for investments. This mathematical approach reduces the errors and risks in decision-making.

This research also demonstrates that the proposed approach can help decision-makers and policymakers to develop strategies for sustaining the development of the Information and Communication Technology industry. According to forecasted MPI, companies with inefficient level $(<1)$ need to be positive in changing or improving their management activities, business trends or size, or any other methods to make progress in the future time. Additionally, by showing an industry average performance index that is always greater than 1 , it shows that the potential for investment is profitable. The decision to invest over the years can be based on the ranking of businesses in the article; investors can rely on it to give themselves a right investment strategy.

Despite providing importance policy implications, this study faces some limitations. Firstly, in Vietnam, there are many companies with ICT-related business but are not yet listed on the stock market, so the review of the industry overview may have many shortcomings. In the future, it is necessary to study the influence of these companies on the ICT industry. Secondly, the more input and output factors in the study, the better development of the company is. Therefore, future studies should focus on finding new evaluation factors affect the effectiveness of ICT companies in Vietnam, such as internal environment factors and external indicators. Finally, the study points out some of the effects of ICT industry development on the overall development of the national economy, as well as giving an idea of industry development to achieve economic efficiency in the world period has shifted to industry 4.0, but has not studied or given evidence in Vietnam, future studies can focus on these issues.

Author Contributions: C.-N.W. contributed to design the research and analysis tools; M.-D.L. collected the data and wrote draft version; T.-D.N. revised and edited the paper. All authors have read and approved the final manuscript.

Funding: This research was partly supported by National Kaohsiung University of Science and Technology, and project number 108-2622-E-992-017-CC3 from the Ministry of Sciences and Technology in Taiwan.

Acknowledgments: The authors appreciate the support from National Kaohsiung University of Science and Technology and Ministry of Sciences and Technology in Taiwan.

Conflicts of Interest: The authors declare no conflict of interest.

\section{References}

1. Mohammed, H.A. The knowledge economy towards a new era of economic development. Int. J. Multidiscip. Thought 2013, 3, 225-236.

2. Vietnam Ministry of Information and Communication. Vietnam's Information and Communication Report; Vietnam Ministry of Information and Communication: Hanoi, Vietnam, 2017.

3. State Security Comission (SSC). Annual Report 2017; SSC: Hanoi, Vietnam, 2017. 
4. VIR. Vietnam Investment Review. Available online: https://www.vir.com.vn/2017-a-year-of-firsts-forvietnamese-stock-market-55243.html (accessed on 26 September 2018).

5. Tavares, G.; Antunes, C.H. A DEA Study of Telecommunications Services in OECD Countries; Annual Conference of The Operational Research Society: Berlin, Germany, 1998; pp. 77-82.

6. Façanha, L.O.; Resende, M. Price Cap Regulation, Incentives and Quality: The Case of Brazillian Telecommunications. Int. J. Prod. Econ. 2004, 92, 133-144. [CrossRef]

7. Pentzaropoulos, G.C.; Giokas, D.I. Comparing the Operational Efficiency of The Main European Telecommunications Organizations: A Quantitative Analysis. Telecommun. Policy 2002, 26, 505-606. [CrossRef]

8. Pentzaropoulos, G.C.; Giokas, D.I. Evaluating Productive Efficiency in Telecommunications: Evidence from Greece. Telecommun. Policy 2000, 24, 781-794.

9. Uri, N.D. Incentive Regulation and the Change in Productive Efficiency of Local Exchange Carriers. Appl. Math. Modeling 2001, 25, 335-345. [CrossRef]

10. Shin, H.W.; Shon, S.Y. Multi-attribute Scoring Method for Mobile Telecommunication Subscribers. Expert Syst. Appl. 2004, 26, 363-368. [CrossRef]

11. Tsai, H.C.; Chen, C.M.; Tzeng, G.H. The comparative productivity efficiency for global telecoms. Int. J. Prod. Econ. 2006, 103, 509-526. [CrossRef]

12. Halkos, G.M.; Nickolaos, G. Global Economic Review: Perspectives on East Asian Economies and Industries. Glob. Econ. Rev. 2007, 36, 167-182. [CrossRef]

13. Kang, C.C. Privatization and production efficiency in Taiwan's telecommunications industry. Telecommun. Policy 2009, 33, 495-505. [CrossRef]

14. Liao, C.H.; Lin, H.Y. Measuring operational efficiency of mobile operators in Japan and Korea. Jpn. World Econ. 2011, 23, 48-57. [CrossRef]

15. Furkan, D.; Emir, S.; Orhan, N. Measuring the Technical Efficiency of Telecommunication Sector within Global Crisis: Comparison of G8 Countries and Turkey. Procedia Soc. Behav. Sci. 2011, 24, 206-218.

16. Emmanouil, S.; Angelo, S. Combining the priority rankings of DEA and AHP methodologies: A case study on an ICT industry. Int. J. Data Anal. Tech. Strateg. 2013, 5, 101-114.

17. Beatriz, C.; Yolanda, F.C.; Antonio, G.J. Stock Price Reaction to Non-financial News in European Technology Companies. Eur. Account. Rev. 2009, 20, 81-111.

18. Sepehr, G.; Khorasani, A.; Rostamy, A.A.; Taheriattar, G.; Rashidirad, M. Performance appraisals of ICT companies in the Tehran stock market: Contradiction with the global trend. Econ. Res. 2016, 29, 529-544.

19. Lee, K.; Park, Y.; Lee, D. Measuring efficiency and ICT ecosystem impact: Hardware vs. software industry. Telecommun. Policy 2018, 42, 107-115. [CrossRef]

20. Wang, C.N.; Nguyen, X.T. Forecasting and Measuring Productivity in Vietnamese Plastic Industry by Using Grey and DEA. Int. Res. J. Adv. Eng. Sci. 2017, 2,141-148.

21. Wang, C.N.; Nguyen, X.T. Applying Grey Model and DEA for the Productivity Evaluation of Vietnamese Hydropower Industry. Int. J. Sci. Res. Publ. 2017. [CrossRef]

22. Wang, C.N.; Nguyen, N.T.; Tran, T.T. Integrated DEA Models and Grey System Theory to Evaluate Past-to-Future Performance: A Case of Indian Electricity Industry. Sci. World J. 2015, 2015. [CrossRef]

23. Wang, C.N.; Lin, H.S.; Hsu, H.P.; Le, V.T.; Lin, T.F. Applying Data Envelopment Analysis and Grey Model for the Productivity Evaluation of Vietnamese Agroforestry Industry. Sustainability 2016, 8, 1139. [CrossRef]

24. Deng, J. Introduction to grey system theory. J. Grey Syst. 1989, 1, 1-24.

25. Tone, K. A slacks-based measure of super-efficiency in data envelopment analysis. Eur. J. Oper. Res. 2002, 143, 32-41. [CrossRef]

26. Fare, S.R.; Grosskopf, S.; Norris, M.; Zhang, Z.Y. Productivity Growth, Technical Progress, and Efficiency Changes in Industrialised Countries. Am. Econ. Rev. 1994, 84, 66-83.

(C) 2019 by the authors. Licensee MDPI, Basel, Switzerland. This article is an open access article distributed under the terms and conditions of the Creative Commons Attribution (CC BY) license (http://creativecommons.org/licenses/by/4.0/). 